\title{
The Impact of Understanding, Religiousity, and Faith towards the Intention to Pay Professional Zakat by Muzakki at Lembaga Amil Zakat Inisiatif Zakat Indonesia (LAZ-IZI) Balikpapan City, East Kalimantan
}

\author{
1 Ana Mulyana, ${ }^{2}$ Sri Wahyuni \\ 1,2Mulawarman University, Kalimantan, Indonesia \\ 19anamulyana@gmail.com, ${ }^{2}$ sriwahyuni@gmail.com
}

\begin{tabular}{|c|c|}
\hline Article Info & Abstract \\
\hline $\begin{array}{l}\text { Article History } \\
\text { Received: July 12, } 2018 \\
\text { Accepted: September 30, } \\
2018\end{array}$ & \multirow[b]{2}{*}{ 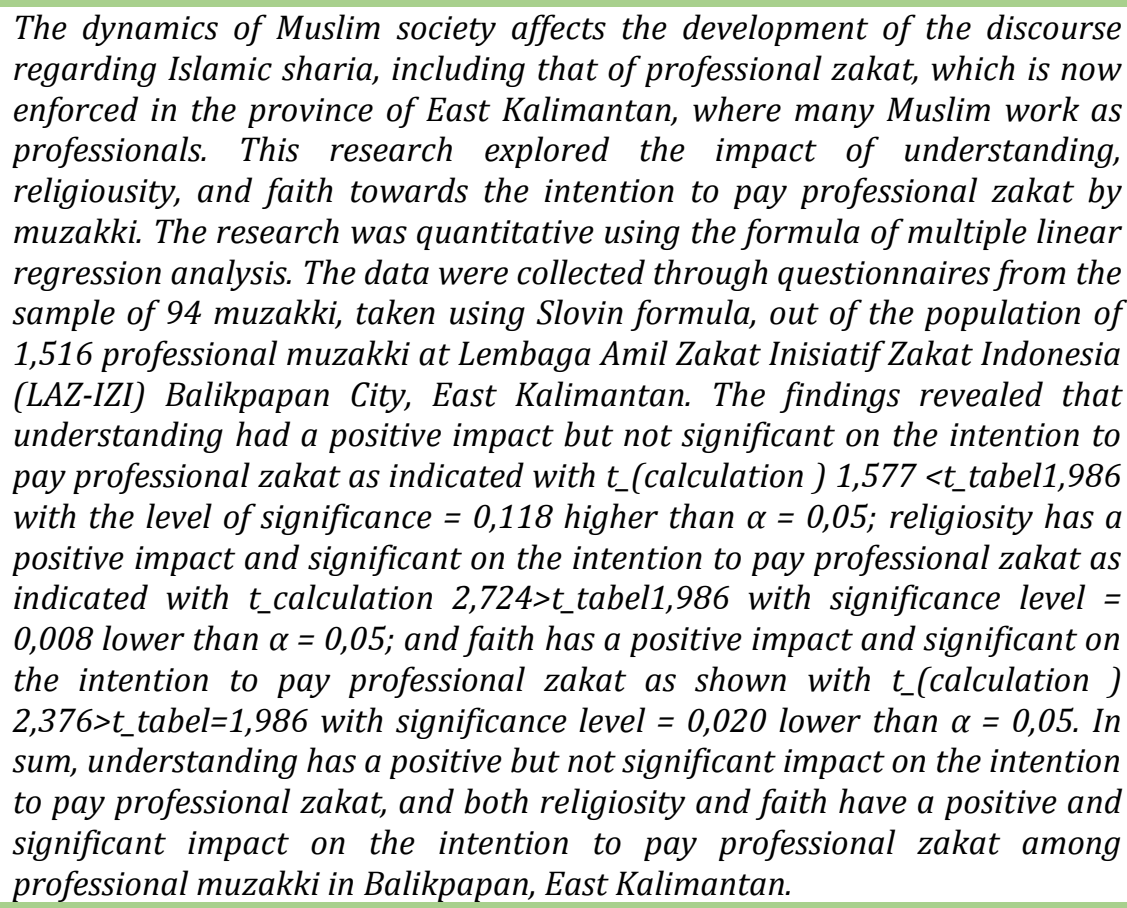 } \\
\hline $\begin{array}{l}\text { Keywords } \\
\text { Understanding, religiosity, } \\
\text { faith, intention, professional } \\
\text { zakat, muzakki }\end{array}$ & \\
\hline $\begin{array}{l}\text { Support by: } \\
\text { dol Crossref }\end{array}$ & \\
\hline
\end{tabular}

\section{PENDAHULUAN}

Zakat profesi memiliki potensi yang sangat besar mengingat banyaknya para pekerja baik yang berada di instansi ataupun di perusahaan swasta.Provinsi Kalimantan Timur ini banyak masyarakat yang terlibat dalam sebuah profesi tentunya akan mendapatkan gaji, upah, insentif, dan bonus.Untuk itu tak heran jika zakat profesi dapat diberlakukan di zaman modern khususnya di Provinsi Kalimantan Timur ini.

Salah satu lembaga amil zakat swasta cabang Provinsi Kalimantan Timur yang melakukan penerapan program zakat profesi ini adalah Inisiatif Zakat Indonesia (IZI). Inisiatif Zakat Indonesia (IZI) mendapatkan legitimasi sebagai Lembaga Amil Zakat Nasional (LAZNAS) berdasarkan Surat Keputusan Menteri Agama Nomor 423 Tahun 2015 pada tanggal 30 Desember 2015 dan telah beroperasi secara resmi dalam mengelola dana zakat masyarakat Indonesia sejak 1 Januari 2016. Adapun muzakki yang sudah berminat menyalurkan dana zakat profesinya di LAZ IZI ini juga cukup banyak. LAZ IZI juga merupakan Lembaga Amil Zakat Nasional yang memiliki banyak 
cabang salah satunya adalah di Provinsi Kalimantan Timur.Jumlah muzakki yang menyalurkan zakat profesi di LAZ IZI adalah sebanyak 1.516 muzakki zakat profesi.

Data diatas juga dapat menjelaskan bahwa banyak masyarakat yang berminat untuk melaksanakan kewajiban membayar zakat profesi ini. Serta menitipkan dana zakatnya untuk disalurkan melalui lembaga amil zakat Inisiatif Zakat Indonesia. Tanpa adanya minat dari mereka untuk berzakat profesi maka potensi zakat profesi untuk menegakkan keadilan ekonomi umat islam tidaklah dapat terealisasi dengan baik.

Fenomena diatas dapat diketahui bahwa seseorang dapat melakukan sesuatu jika memiliki minat dan melakukannya.minat dapat dipengaruhi oleh beberapa faktor. Berbagai macam penelitian tentang minat seorang muzakki dalam menyalurkan zakat dapat terpengaruhi oleh pemahaman.Faktor lain yang dapat mempengaruhi minat seorang muzakki adalah religiusitas dan kepercayaan seorang muzakki terhadap lembaga amil zakat tersebut.

Maka faktor-faktor yang diambil dalam penelitian ini adalah pemahaman dan religiusitas serta kepercayaan muzakki LAZ IZI untuk membayar zakat profesi.Hal ini menjadi landasan sangatlah berpengaruh terhadap minat mereka. Minat mereka untuk melakukan kewajiban zakat profesi inilah ang akan meningkatkan potensi zakat profesi di Kota Balikpapan melalui salah satu organisasi zakat yaitu LAZ IZI.

Muzakki yang memiliki pemahaman sangat baik tentang zakat profesi maka akan mempengaruhi minat muzakki terhadap zakat profesi akan tinggi. Begitu juga religiusitas seorang muzakki baik maka akan mempengaruhi minat muzakki terhadap zakat profesi juga akan tinggi. Faktor terakhir yaitu kepercayaan muzakki terhadap LAZ IZI itu sendiri juga dapat mempengaruhi rminat muzakki untuk melakukan zakat profesi. Jika minat muzakki LAZ IZI dalam membayar zakat profesi meningkat maka potensi zakat profesi akan meningkat serta dapat tersrap baik pada LAZ IZI. Kemudian dana zakat tersebut dapat di distribusikan oleh LAZ IZI secara optimal sehingga mendatangkan manfaat jangka panjang baik untuk muzakki ataupun mustahik yang ada di LAZ IZI.

Penjelasan dan fenomena dapat dilakukan penelitian dengan judul " Pengaruh Pemahaman dan Religiusitas serta Kepercayaan terhadap Minat Membayar Zakat Profesi oleh para Muzakki Pada Inisiatif Zakat Indonesia Cabang Kaltim Kota Balikpapan".

\section{METODE}

Populasi dalam penelitian ini merupakan jumlah keseluruhan jumlah muzakki zakat profesi yang aktif membayar pada LAZ IZI dari januari tahun 2016 hingga Oktober 2017 adalah sebanyak 1.516 muzakki zakat profesi. Adapun kriteria populasi dalam penelitian ini adalah muzakki memiliki pekerjaan di Instansi Pemerintah atau Non Pemerintah yang mendapatkan gaji setiap bulan secara rutin. Dengan menggunakan Slovin maka jumlah sampel didapatkan sebesar 93,81 maka dibulatkan dari sampel menjadi 94 sampel. Sampel dalam penelitian ini adalah muzakki memiliki pekerjaan di Instansi Pemerintah atau Non Pemerintah yang mendapatkan gaji setiap bulan secara rutin mencapai nisab.

Pengukuran dalam penelitian ini menggunakan skala likert dengan pengisian kuisioner yang disusun dalam bentuk pertanyaan dan responden diminta untuk mengisi daftar pertanyaan tersebut dengan cara memberi tanda centang (V) pada lembar kuisioner. Menurut Sugiyono (2012) skala likert digunakan untuk mengukur sikap, pendapat dan persepsi seseorang atau sekelompok orang tentang fenomena sosial.Pengukurannya menggunakan skala likert yang berisi lima tingkat preferensi jawaban dengan pilihan yang berisikan simbol, alternatif jawaban dan nilai setiap 
jawaban yang diberikan. Dengan nilai yang diberikan setiap jawaban dari rentang nilai $1-5$.

\section{HASIL DAN PEMBAHASAN}

Berdasarkan hasil analisis koefisien, maka model regresi linear berganda adalah sebagai berikut

$$
\mathrm{Y}=4,688+0,120 \mathrm{X} 1+0,172 \mathrm{X} 2+0,104 \mathrm{X} 3\urcorner+\mathrm{e}
$$

Interpretasi dari regresi di atas adalah sebagai berikut: ini berarti jika semua variabel bebas memiliki nilai nol (0) maka nilai variabel terikat (a) sebesar 4,688 Nilai koefisien pemahaman untuk variabel X1 sebesar 0,120. Hal ini mengandung arti bahwa setiap kenaikan pemahaman (X1)semakin paham muzakki tentang zakat profesi maka variabel minat $(\mathrm{Y})$ akan naik sebesar 0,120 dengan asumsi bahwa variabel bebas yang lain dari model regresi adalah tetap. Nilai koefisien religiusitas untuk variabel X2 sebesar 0,172.Hal ini mengandung arti bahwa setiap kenaikan religiusitas (X2)semakin setuju muzakki tentang nilai religiusitas yang ada didalam diri mereka maka variabel minat (Y) akan naik 0,172 dengan asumsi bahwa variabel bebas yang lain dari model regresi adalah tetap.Nilai koefisien kepercayaan untuk variabel X3 sebesar 0,104.Hal ini mengandung arti bahwa setiap kenaikan kepercayaan(X3) semakin percaya seorang muzakki terhadap LAZ IZI dalam mengelola dana zakat profesi maka variabel minat (Y) akan naik 0,104 dengan asumsi bahwa variabel bebas yang lain dari model regresi adalah tetap.

Nilai Uji T (parsial)dapat dilihat pada tabel berikut ini:

\begin{tabular}{|l|c|c|c|c|}
\hline \multicolumn{1}{|c|}{ Hipotesis } & Arah & Koefisien & Value & Kesimpulan \\
\hline $\begin{array}{l}\text { Pemahaman berpengaruh positif } \\
\text { dan signifikan terhadap minat } \\
\text { membayar zakat profesi oleh } \\
\text { muzakki }\end{array}$ & Positif & 0.120 & 0.118 & $\mathrm{H}_{1}$ Ditolak \\
\hline $\begin{array}{l}\text { Religiusitas berpengaruh positif dan } \\
\text { signifikan terhadap minat } \\
\text { membayar zakat profesi oleh } \\
\text { muzakki }\end{array}$ & Positif & 0.172 & 0.008 & $\mathrm{H}_{2}$ Diterima \\
\hline $\begin{array}{l}\text { Kepercayaan berpengaruh positif } \\
\text { dan signifikan terhadap minat } \\
\text { membayar zakat profesi oleh } \\
\text { muzakki }\end{array}$ & Positif & 0.104 & 0.020 & $\mathrm{H}_{3}$ Diterima \\
\hline
\end{tabular}

Dari persamaan diatas dapat diartikan bahwa variabel pemahaman (X1), religiusitas (X2) dan kepercayaan (X3) terhadap minat (Y) masyarakat membayar zakat profesi di LAZ IZI Kaltim Kota Balikpapan diperoleh koefisien regresi yang bernilai positif. Nilai ${ }^{2}$ (koefisien determinasi) sebesar 0,273 yang memiliki arti bahwa persepsi tentang pemahaman, religiusitas dan kepercayaan memberikan pengaruh terhadap minat muzakki membayar zakat profesi pada LAZ IZI Kaltim Kota Balikpapan sebesar 27,3\%, sedangkan sisanya sebesar 72,7\% dipengaruhi oleh variabel lain yang tidak diteliti oleh penulis. Pengaruh Pemahaman Terhadap Minat Muzakki Membayar Zakat Profesi

Hasil pengujian hipotesi pertama diperoleh t_(hitung ) 1,577<t_tabel1,986 dengan tingkat signifikan $=0,118$ lebih besar dari $\alpha=0,05$. Artinya variabel pemahaman (X1) memiliki pengaruh positif tidak signifikan terhadap minat (Y) membayar zakat profesi oleh muzakki LAZ IZI Kaltim Kota Balikpapan.Hasil analisis diatas menunjukkan bahwa pemahaman memiliki pengaruh positif terhadap minat membayar zakat profesi.Nilai 
tidak signifikan menunjukkan bahwa indikator yang digunakan tidak terpercaya untuk dijadikan ukuran dalam menilai pemahaman seseorang.

Nilai tidak signifikan pemahaman terhadap minat dapat diakibatkan muzakki yang paham akan zakat profesi tetapi kemungkinan mereka tidak mau membayar ke LAZ IZI. Hal ini dapat disebabkan oleh beberapa faktor beberapa diantaranya adalah seperti muzakki yang ingin menyalurkan langsung zakat profesinya kepada mustahik yang termasuk dalam 8 asnaf, kebutuhan administrasi yang lumayan banyak ketika harus menyalurkan ke LAZ IZI.

Pengaruh Religiusitas Terhadap Minat Muzakki Membayar Zakat Profesi

Hasilpengujian hipotesis pertama diperoleh t_hitung 2,724>t_tabel1,986.dengan tingkat signifikan $=0,008$ lebih kecil dari $\alpha=0,05$. Artinya variabel religiusitas (X2) memiliki pengaruh positif signifikan terhadap minat (Y) membayar zakat profesi oleh muzakki LAZ IZI Kaltim Kota Balikpapan. Hal ini memiliki arti bahwa keyakinan muzakki bahwa bersedekah akan dilipat gandakan hartanya, pengamalan salah satu rukun islam, penghayatan seorang hamba atas rasa syukur, pengetahuan akan kewajiban membayar zakat bagi umat muslim dan sebagai konsekuensi atas rezeki yang mencapai nisab dapat mempengaruhi serta mendorong minat muzakki membayar zakat profesi di LAZ IZI Kaltim Kota Balikpapan.

Kesadaran masyarakat Kaltim dalam membayar zakat profesi dapat terjadi karena adanya nilai religius yang dimiliki oleh mereka semakin bertambah. Keimanan seseorang akan bertambah jika melakukan semua kewajiban yang diajarkan oleh agamanya. Oleh karena itu maraknya kesadaran masyarakat dalam menjalankan perintah Allah di buktikan dengan membayar zakat.

Pengaruh Keprcayaan Terhdap Minat Muzakki Membayar Zakat Profesi

Hasilpengujian hipotesi pertama diperoleh t_hitung 2,376>t_tabel=1,986dengan tingkat signifikan $=0,020$ lebih kecil dari $\alpha=0,05$. Artinya variabel kepercayaan (X3) memiliki pengaruh positif signifikan terhadap minat $(\mathrm{Y})$ membayar zakat profesi oleh muzakki LAZ IZI Kaltim Kota Balikpapan. Hal ini menunjukan bahwa LAZ IZI memiliki keterbukaan dalam pengelolaan dana zakat, kompeten dalam menjalankan tugas, kejujuran dalam memberikan informasi, menjalankan sesuai dengan visi dan misi, mempertanggung jawabkan kinerja dengan memberikan laporan keuangan, sharing kepada para muzakki dengan membuka layanan konsultasi, menghargai kepada muzakki dan mustahik dapat berpengaruh serta mendorong minat muzakki membayar zakat profesi di LAZ IZI Kaltim Kota Balikpapan.

Kepercayaan muzakki terhadap LAZ merupakan hal penting yang harus diperhatikan oleh lembaga tersebut. Karena dalam menyalurkan dana zakat memiliki banyak ketentuan dan pertimbangan sehingga tidaklah mudah bagi lembaga untuk mendapatkan suatu kepercayaan dari muzakki. Kepercayaan yang dimiliki oleh LAZ harus dijaga dan dibuktikan dengan baik dan sesuai.

\section{SIMPULAN}

Variabel pemahaman (X1) memiliki pengaruh positif tidak signifikan terhadap minat (Y) muzakki membayar zakat profesi di LAZ IZI Kaltim Kota Balikpapan.Variabel religiusitas (X2) memiliki pengaruh positif signifikan terhadap minat (Y) muzakki membayar zakat profesi di LAZ IZI Kaltim Kota Balikpapan.Variabel kepercayaan (X1) memiliki pengaruh positif signifikan terhadap minat (Y) muzakki membayar zakat profesi di LAZ IZI Kaltim Kota Balikpapan.

Pemahaman masyarakat Kaltim tentang zakat profesi pada LAZ IZI yang masih kurang, dapat dijadikan sebuah evaluasi bagi amil LAZ IZI untuk dapat meningkatkan pemahaman muzakki tentang zakat profesi. Upaya yang dapat dilakukan LAZ IZI Kaltim 
Kota Balikpapan adalah dengan melakukan suatu layanan berupa sosialisasi dan edukasi tentang zakat profesi yang dapat dilakukan oleh para ulama atau ustad setempat yang dapat menjelaskan dengan baik tentang kewajiban zakat profesi. Implementasi nilai religiusitas seseorang dapat di lihat dengan mereka menjalankan ibadah mahdah atau non mahdah dengan baik.Kepada para pengurus dan pengelola LAZ IZI Kaltim Kota Balikpapan agar dapat memberikan komitmen dan peningkatan layanan yang lebih baik lagi dalam melakukan tugas sebagai lembaga amil zakat di Indonesia. Hal ini dapat mendorong lebih cepat minat muzakki dalam menyalurkan dana zakat profesinya kepada LAZ IZI Kaltim Kota Balikpapan.Diharapkan untuk penelitian selanjutnya agar dapat menambah dan meneliti dengan menggunakan faktor lain yang diduga memiliki pengaruh yang lebih kuat terhadap minat muzakki. Mengingat $72,6 \%$ minat membayar zakat profesi di pengaruhi oleh faktor lain.

\section{DAFTAR PUSTAKA}

[1] Ancok, D; Suroso, F.N 2001.Psikologi Islam, Penerbit Pustaka Pelajar. Jakarta

[2] Attamimi A. Hamid S, 2008. Teori Perundang-Undangan Indonesia Suatu Sisi Ilmu Pengetahuan Perundang-undangan Indonesia yang Menjelaskan dan Menjernihkan Pemahaman, Perpustakaan UI, Jakarta.

[3] Daryanto, 2008.Evaluasi Pendidikan, Rineka Cipta: Jakarta.

[4] Kahmad, Dadang. 2009. Sosiologi Agama. PT. Remaja Rosdakarya. Bandung

[5] Nur'aini, Hanifah; M. Rasyid R 2015.Pengaruh Kualitas Pelayanan, Citra Lembaga dan Religiusitas terhadap Minat untuk menyalurkan Zakat Profesi. Universitas Sunan Kalijaga. Yogyakarta.

[6] Qardhawi, Yusuf. 2004.Manajemen Zakat Kontemporer, Media Insani Press, Tulungsari,

[7] Slameto, 2010.Belajar dan Faktor-Faktor yang Mempengaruhinya. Rineka Cipta. Jakarta

[8] Sugiyono,2013.Metode Penelitian Pendidikan Pendekatan Kuantitatif, Kualitatif, dan $R \& D$. Alfabeta. Bandung

[9] Sumarwan, Ujang. 2011 Perilaku Konsumen: Teori dan Penerapan dalam Pemasaran.Ghalia Indonesia. Bogor.

[10] Suparman, Atwi. 2012. Desain Instruksional Modern. Erlangga. Bandung

[11] Wibowo, 2006.Manajemen perubahan, PT.Grafindo Persada. Jakarta 